\title{
Obituary
}

\section{Dr Mary Myers FRCPsych}

\section{Formerly consultant in the psychiatry of learning disability, Sheffield Health Authority}

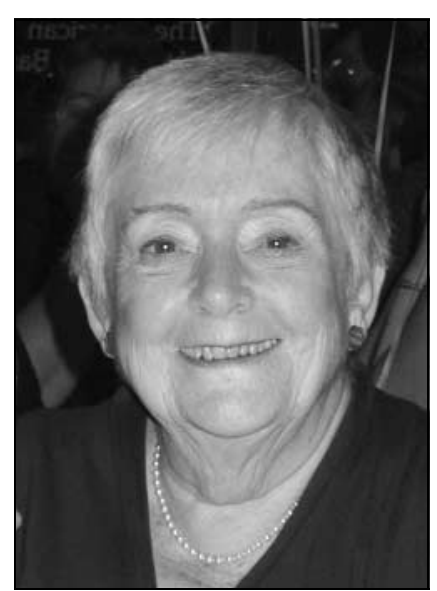

Mary Myers was a leading pioneer in the field of the psychiatry of mental handicap (renamed learning disability) at a time of rapid change when mental hospitals were gradually being emptied of their patients. As a result of work carried out by Jack Tizard and others in the 1960s, it was shown that people with learning disabilities had potential for independent living that was far in advance of

anything they were achieving in hospital. In the 1970s, UK government policy, driven partly by the findings of such studies and partly by scandals of poor and inhumane care of people with learning disabilities in large institutions, was to seek an end to large-scale institutional care and to promote the development of services providing care and support in the community.

In 1974, Mary took up the post of consultant psychiatrist in mental handicap in Rotherham with the specific task of establishing a community-based service. Her single-author paper in the BMJ (1982) summarised the 'First seven years of a new NHS mental handicap service'. In it one can see the clear foundations of the subsequent reshaping of social and health provision over the remainder of the 20th century. In characteristic style she concluded that 'Without a supportive matrix of co-ordinated statutory agencies ( . . . ) both modern professional skills and voluntary resources will not be exploited to the full for this very vulnerable group. Future developments must be based on clearly defined and declared principles'.

Following a failed piloting of the government's new strategy, Better Services for the Mentally Handicapped, in 1982 she was appointed lead consultant in the Sheffield Health Authority; her job was to 'turn the service around'. Her approach was one of encouragement of health and social care professionals of all backgrounds and positions to learn from the experience of others, to bring people together in conversations and exchanges of ideas, innovations and knowledge. Her enthusiasm, charisma and relentless networking brought leading and inspirational international figures from a wide spectrum of expertise to Sheffield and the UK to work alongside professionals, families, carers and people with learning disabilities themselves. She earned their lifelong admiration and respect for her genuine warmth and support, and her encouragement of professionals' practice to be firmly rooted within the principles of person-centred service development and delivery.
Mary's influence was not merely local. As a member of the National Development Team during the 1970s, way ahead of her time, she sought to improve services around the country and was a member of the group which produced the Kings Fund's seminal publication, An Ordinary Life. This led to fundamental changes in the way in which people with learning disabilities were to be perceived and thus supported. The underlying principles were to move away from seeing people as patients in a perpetual state of dependency and passive recipients of resources to their promotion as citizens with rights like any other and living in 'ordinary houses in ordinary streets'.

Colleagues have described Mary as one of the greatest of the early advocates for, and champions of, people with learning disabilities who really did help to shift attitudes and aspirations. In the words of the late Herb Lovett, psychologist, she recognised the 'mutuality of our human condition' in emphasising values of inclusion, empowerment and respect, and thereby making a fundamental and tangible difference to the well-being of her patients, their families and those who worked with her and loved her.

I know from my own experience that, although she was an unconventional teacher, she had a remarkable ability to inspire and motivate and shape the understanding of others through her uncomplicated, humanistic and person-centred approach combined with an uncanny ability to bring people together to learn from each other. As a psychiatry trainee in Sheffield in the late 1980s, I can recall sitting at Mary Myers' kitchen table while she pottered about alternately making coffee, thrusting a selection of interesting cuttings, papers and books under my nose and talking with joyful compassion and empathy about various patients, funny situations, the most recent snippet of information or ideas that had caught her eye or her ear. This was my regular supervision in 'mental handicap' and it was quite unlike any experience of learning in medicine or psychiatry that I had come across before. This was what Mary called 'learning at Nelly's elbow' and here the elbow belonged to a psychiatrist who was deeply committed to, and moved by, the lived experiences of people with intellectual disabilities, their families, their histories of institutionalisation, of stigma and abuse, but also of triumphs and insights and their enrichment of the lives of others. Mary's main interest was not so much in syndromes and pathology but in the reality of being a person with a disability and how one might overcome the barriers that the world constantly puts in your way.

Alice Mary Martin was born in Hornsey on 9 December 1930 and studied at the Welsh National School of Medicine in Cardiff, qualifying in 1960. In 1955 she married Ken Myers, who was training in psychiatry and went on to work at Fulbourn Hospital in Cambridge. Mary, who was bringing up their three children, David, Sarah and Peter, undertook postgraduate training in developmental psychiatry at the Ida Darwin Hospital, Cambridge. The experiences of raising a family, and in particular of understanding the development and needs of a family member with Asperger syndrome, were a bedrock and constant reference point for Mary's professional training and practice. This no-nonsense practicality combined with an astute clinical and systemic knowledge and intuition endeared her to her patients 
and their families who found themselves in the company of a doctor they could trust and who spoke their language.

Although she retired in 1991, the reality is that Mary never really gave up working. Her career as a psychiatrist had not merely been an employment but was an expression of her core beliefs, values and respectful curiosity about people and how they can work together in genuine partnerships for the common good. Mary continued to teach, advise, support and learn from others and at the time of her death was still learning and relishing being in the company of a younger generation while studying for a masters degree in autism.

She died on 20 May 2013 and is survived by her husband Ken and their children.

Dr Roger Banks

\section{Interview with Professor William Alwyn Lishman}

First published in Neuropsychiatry News, Winter 2012, issue 6. Reprinted with permission.

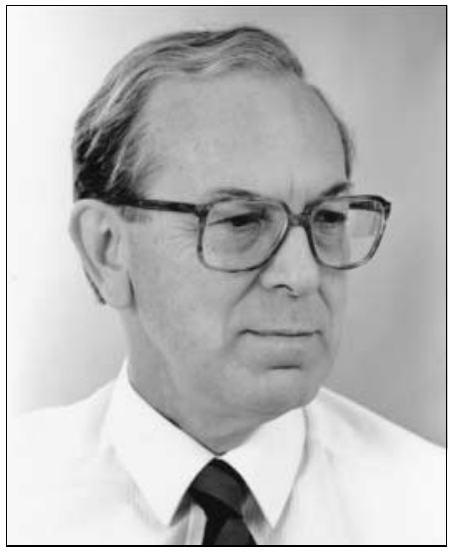

In March 2012, I had the great pleasure of talking with Professor Alwyn Lishman for the Neuropsychiatry Newsletter in the first of what I hope to become a regular series of interviews of the great and the good in neuropsychiatry. I am grateful to Professor Lishman for his indulgence and patience and also to Dr Jonathan Bird who kindly orchestrated the meeting and joined us in the discussion.

\section{Am I right in thinking you trained initially as a neurologist?} I didn't have what you'd call a proper training. What happened was that I had to go into the army as a national serviceman. And when I went into the army l'd done 6 months of neurosurgery so I was drafted to the head injury hospital. And there I got my membership (MRCP) within the first year. And I took it, with minimal revision, and just happened to pass it, which was a tribute to my medical school I suppose. At that point the army was running down tremendously and they had no neurology specialist, so I was made an army specialist neurologist. I was put in charge of the hospital, medical division and given a rank of major, having just been a captain for a few months. So I'd been a sort of consultant neurologist in the army. Then I was beckoned to go to the Radcliffe, and Charles Whitty went to Australia for 2 months and I was a locum consultant neurologist. So I'd had an extraordinarily accelerated career to function as a neurologist.

\section{How then did you cross over to psychiatry?}

I can remember the very day I made the decision. A very great neurologist visited the hospital and I realised with a terrible thud that there was nothing he could do for patients that I couldn't do, that the only thing he had over me was academic knowledge of the brain. And that was not my idea of being a doctor. So I thought: I want to stick with what I've got but broaden it. So that's when I went to the Maudsley and learned about all the other avenues: talking, social psychiatry, holistic psychiatry. There were so many wonderful facets to psychiatry that there weren't in neurology. I found that tremendously liberating and that's what I enjoy doing as a doctor. I found some of the patients a terrible bore and a bind, but you always get that. But they were so much more of a challenge than neurological patients. By the time you've seen your fiftieth MS patient you really were just distressed for them. It was very difficult to know what to do next for them. Even Parkinson's disease - there was very little you could do. Drugs hadn't come in properly. So it was a barren field for me as a clinician.
Given all the treatments available today in neurology do you think you would make the same decision now?

No, it would be much harder for me to make that decision because not only have they got more treatment and more avenues, but being a psychiatrist is much less appealing as far as I can see. Community psychiatry would never have appealed to me, sitting around in a circle with lots of nurses. I think it's very hard to get the right clinical atmosphere that suits your personality. I think I was always rather bossy - not obviously bossy, but secretly incredibly bossy. And that's not good in modern psychiatry. I'd have found it hard being part of a team. Actually, I know what I'd have done: I'd have quickly become a proper neuropsychiatrist!

So, how did it come about that you became a neuropsychiatrist? So I was at the Maudsley resisting becoming an academic for the simple reason that I thought of the awful things that happened to academics at the Maudsley. If they fell out with the head of department they perished. Aubrey Lewis was very autocratic. Aubrey Lewis wanted me to become a physiologist. He sent for me and said: 'You're wasting your time in psychiatry'. I was also a physiologist before I came into medicine. I did quite a bit of work and published quite a few papers. And he said: 'We need a professor of physiology who is also a psychiatrist'. And I resisted it.

The first job I applied for was senior lectureship at the Royal London. And I didn't get it. It went to Arthur Crisp. The next one I applied for was at King's [King' College London] but they appointed a man who had come from Sheffield and he lasted about 6 months and went to America. This sort of thing happened in those days. It didn't matter how many prizes you got. And at that point Dennis Lee sent for me. He'd been on the appointments committee and he said: 'I've got to tell you Lishman, I was the one who persuaded them not to have you. You're a backroom boy'. This was going around because I was doing physiology on rats, as well as doing clinics. And it was very easy to get the wrong label stuck to you. So that was that.

\section{Where does Queen's Square fit in?}

That was the third one I applied for. I went to see Eliot Slater. Eliot had a terrible time there. He got the funds together for a chair and the medical committee voted not to accept them. So he said to me: 'Go there, have a wonderful time but don't stay more than a couple of years, because they'll do to you what they did to me'. In fact they were very welcoming to me and very helpful indeed. When Denis Hill beckoned me to come back [to the Maudsley] I thought: I'll do what Eliot said, I've had my two years and it's been interesting. Also, some of the neurologists were extremely hostile to a psychiatrist. I won't mention their names even now, but the ones who were wonderful I will: Dennis Williams, Macdonald Critchley and Charles Simons were marvellous. But others were very dismissive. They would ask you to see a patient and you'd spend hours, and you'd come back tomorrow and the patient would have been sent out. They weren't good doctors some of them. They were fascinated by patients as specimens, really. I didn't want to live in that world forever.

\section{When were you at the Maudsley?}

The first 12 years I was a consultant from 1967 onwards. I was a general psychiatrist there, and I took my share of all the patients 